\title{
Desindustrialización y estancamiento económico en El Salvador
}

\author{
Luis René Cáceres
}

\section{Resumen}

En este trabajo se analiza la desindustrialización en El Salvador, un fenómeno que afecta a los países de América Latina desde los años ochenta y tiene repercusiones en términos de estancamiento económico y pérdida de empleos de calidad. En la primera sección se presenta una reseña de la literatura seleccionada sobre este tema. A continuación se examinan las causas de la desindustrialización en El Salvador, en primer lugar la posibilidad de que las remesas ocasionen un fenómeno de enfermedad holandesa. Descartada esta hipótesis, se examinan las repercusiones de las reformas económicas llevadas a cabo en los años noventa y, mediante la estimación de ecuaciones de cointegración, se encuentra evidencia de que la extrema apertura comercial constituye el motivo principal de la contracción de los sectores de bienes transables. El trabajo termina con una serie de recomendaciones y conclusiones.

\section{Palabras clave}

Desindustrialización, condiciones económicas, crecimiento económico, política comercial, indicadores económicos, El Salvador

Clasificación JEL

011, 018, 054

Autor

Luis René Cáceres es Doctor en Economía de la Universidad de Utah, Estados Unidos. luisrenecaceres@gmail.com 


\section{Introducción}

Por desindustrialización se entiende la merma de la participación del sector manufacturero en el producto interno bruto (PIB) o la reducción del porcentaje que el empleo en este sector representa en el empleo total. Este fenómeno se observa desde la década de 1970 en los países desarrollados y a partir de la década siguiente en los países en desarrollo, especialmente los de América Latina. En esa región, la media del empleo en el sector manufacturero como porcentaje del empleo total disminuyó del 16,5\% en 1980 al 14,2\% en 2003 (Palma, 2008). La pérdida de participación en el producto fue aún más marcada, del 28,1\% al 16,7\% entre 1960 y 2003 (Palma, 2008). Se observa que, a medida que la participación de la industria manufacturera disminuye, el valor agregado del sector de servicios en el PIB aumenta en forma sostenida.

La desindustrialización en los países desarrollados se ha interpretado como un efecto del proceso de desarrollo económico en sí, pues el aumento de la productividad permite a la industria operar con cantidades de mano de obra decrecientes. Sobre la base de datos de 1990, Rowthorn (1994) sostiene que la participación del sector manufacturero en el empleo total en los países desarrollados empieza a decaer cuando se alcanza un ingreso per cápita de 12.000 dólares. Sin embargo, los países de América Latina han experimentado desindustrialización con valores de ingreso per cápita más bajos y sin haber logrado establecer un parque industrial con altos niveles de tecnología, con consecuencias adversas en el proceso de desarrollo. Existe evidencia de que la industria manufacturera es el principal motor del crecimiento económico y de la productividad. Esta posición, que data de los trabajos de List $^{1}$, fue posteriormente postulada por Kaldor (1967) y cuenta con evidencia empírica recogida en diversos trabajos (Pieper, 2003; Wells y Thirlwall, 2003). De hecho, la disminución de la productividad en los países de América Latina desde mediados de los años ochenta coincide con sus experiencias de desindustrialización (Cáceres, 2015; Palma, 2010). Cabe destacar que la desindustrialización en los países de América Latina en lo que va de este siglo es más marcada que en los países de otras regiones (Rodrik, 2015).

Este sector es fuente de buenos empleos, adquisición de destrezas y generación y difusión de tecnología, y recibe las mayores erogaciones en materia de investigación y desarrollo. Además, los bienes manufacturados tienen altas elasticidades de ingreso y precio en el mercado internacional, un factor que contribuye al dinamismo de las exportaciones. El crecimiento del sector manufacturero muestra correlaciones positivas con indicadores sociales como la esperanza de vida al nacer y la tasa de alfabetización, entre otros, y ha sido determinante de los procesos de democratización en los países desarrollados (Rodrik, 2015).

En este trabajo se busca establecer el origen del acentuado proceso de desindustrialización en El Salvador, donde la participación de la industria manufacturera en el PIB se redujo del 25\% al 20\% entre 2001 y $2013^{2}$. En consonancia con la desindustrialización, la economía salvadoreña muestra una persistente tendencia al estancamiento desde mediados de los años noventa hasta el presente, período en que la tasa media de crecimiento fue del 1,92\%. Asimismo, la participación del sector agropecuario en el PIB disminuyó del 14,56\% en 1990 al 10,84\% en 2013. La contracción relativa de los sectores transables ocurrió en el contexto de intensos programas de reformas económicas que se llevaron a cabo en la década de 1990 y de la adopción del dólar como moneda de curso legal en 2001. Otro importante elemento del marco macroeconómico de las tres últimas décadas radica en la cuantiosa cantidad de remesas recibidas por el país, que alcanzó el 16,34\% del producto en 2013

\footnotetext{
1 De acuerdo con List (1983), la industria es la madre y el padre de la ciencia, la literatura, las artes, la ilustración, la libertad, las instituciones útiles, los poderes nacionales y la independencia (citado por Ho, 2006).

2 De acuerdo con datos sobre los trabajadores que cotizan en el Instituto Salvadoreño del Seguro Social (2014), la participación del sector manufacturero en el empleo total también muestra una tendencia declinante, al pasar del 28,82\% en 2003 al $21,75 \%$ en 2013.
} 
y llevó al consumo privado a niveles superiores al 90\% del producto. Es irónico que, no obstante los intentos de modernización económica y la abundante entrada de recursos externos, el valor agregado de los bienes transables en el PIB haya disminuido.

El trabajo se divide en cinco secciones, incluida esta Introducción. En la segunda sección se presenta una reseña de la literatura más relevante sobre la desindustrialización y en la tercera la fuente de datos utilizada. En la cuarta sección se realiza un examen de las posibles explicaciones de la desindustrialización en El Salvador. Se muestra que la importación de bienes de consumo ha aumentado de manera desmedida como resultado de la rebaja de los aranceles de importación y ha desplazado la producción nacional de bienes transables. Se deduce, por tanto, que la causa de la desindustrialización reside en las reformas de comercio exterior llevadas a cabo en los años noventa. Usando métodos de cointegración, se investiga la existencia de una relación entre el valor agregado de los sectores transables e indicadores de la reforma comercial. En la quinta y última sección se realiza una serie de consideraciones finales.

\section{Reseña de literatura seleccionada}

Rowthorn y Ramaswamy (1998) analizaron el caso de 18 países desarrollados con datos anuales de 1963-1994 para discernir si la desindustrialización obedecía a causas internas de la economía de esos países o derivaba de las relaciones comerciales con otras naciones. Los resultados de la estimación de ecuaciones econométricas indicaron que las variables de carácter interno, como la mayor productividad del sector manufacturero con respecto al sector de servicios y la reducción de la tasa de inversión y del precio de las manufacturas, explicaban el $80 \%$ de la disminución del empleo en este sector con respecto al empleo total. El 20\% restante se explicaba por variables externas, como la importación de bienes manufacturados de países en desarrollo. Los autores también encontraron que el papel negativo de esta última variable se manifestaba en su impacto en el incremento de la productividad del sector y concluyeron que la desindustrialización obedecía a factores económicos internos propios de cada país. En el análisis empírico de Lawrence (1987) sobre Alemania, Francia y Suecia, basado en datos de 1973 y 1985, se encontró que la desindustrialización se debía a variables internas, resultado que también obtuvieron Dollar y Wolff (1993) para el caso de los Estados Unidos. En un trabajo reciente, Lawrence y Edwards (2013) demostraron que la merma del empleo en el sector manufacturero de ese país obedecía al aumento de la productividad, unido a una decreciente demanda de bienes industriales con respecto a la demanda de servicios.

Por otra parte, Saeger (1997) señala que en los países de la Organización para la Cooperación y el Desarrollo Económicos (OCDE) la reducción de la participación del valor agregado de la industria manufacturera en el producto coincidió con el aumento del comercio con los países en desarrollo. A partir de datos quinquenales del período 1970-1990, este autor estimó ecuaciones para un panel de 23 países, cuyos resultados indicaron que la importación de bienes manufacturados desde países en desarrollo tenía efectos negativos en la participación del empleo en el sector manufacturero en el empleo total y del valor agregado de este sector en el PIB, aun cuando las ecuaciones incluían variables de capital humano, productividad, ingreso per cápita y exportación de petróleo (esta última para determinar la presencia de la enfermedad holandesa). El impacto negativo de la importación de bienes manufacturados representaba entre el $25 \%$ y el $30 \%$ de la varianza de la desindustrialización de los países de la OCDE, mientras que la productividad y la exportación de petróleo constituían alrededor del $40 \%$.

Nickell, Redding y Swaffield (2008) estimaron ecuaciones para cada país de la OCDE, expresando la participación de los distintos sectores económicos en el PIB en función de la productividad total de los factores, el nivel de educación, los precios relativos entre sectores y la inversión. Los resultados 
indicaron que los efectos de estas variables eran diferentes de un país a otro. En todos los países, la mayor contribución a la desindustrialización se originaba en los precios relativos de los bienes manufacturados con respecto a los precios de otros bienes, mientras que la productividad total de los factores y la expansión del capital humano la frenaban. Además, el cambio de la participación sectorial en el producto era más rápido en los países donde las leyes de protección del empleo eran menos estrictas.

En el caso de Suecia, Lind (2011) mostró que la participación del empleo y el valor agregado del sector manufacturero en el empleo total y el PIB, respectivamente, comenzó a disminuir en 1950 hasta estabilizarse a inicios de los años setenta. Más adelante, el aumento de la productividad del sector - que creció con mayor rapidez que la del sector de servicios - se tradujo en una reducción de su participación en el empleo total y en un aumento de la participación de su valor agregado en el producto. Este es un caso en que la inferioridad de los precios del sector manufacturero con respecto a los del sector de servicios estimula la demanda de manufacturas y, en consecuencia, da lugar a una reindustrialización.

Tregenna (2011) identificó 52 países donde la participación del sector manufacturero en el PIB aumentó en el período 1985-2005 y señaló la importancia de que los países en desarrollo establezcan un proceso de reindustrialización, en particular mediante la adopción de políticas industriales que contribuyan a evitar el desplazamiento de la industria nacional por las importaciones ${ }^{3}$.

Dasgupta y Singh (2006) apuntan que, dado que el sector manufacturero es el principal sector de la economía, la desindustrialización tendrá costos en términos de lento crecimiento económico. Los autores usan datos del período 1990-2000 relativos a 48 países para estimar ecuaciones que representan la relación conocida como primera ley de Kaldor, que establece un nexo directo entre el aumento del valor agregado del sector manufacturero y el incremento del PIB. Sus resultados confirmaron la existencia de esta relación, pues el crecimiento del sector manufacturero en 1 punto porcentual estaba asociado a un incremento del PIB de 0,4 puntos. Esto confirma la importancia de este sector para impulsar el crecimiento económico.

Palma (2005 y 2008) propuso varias explicaciones para la desindustrialización. La primera radica en la relación de $U$ invertida entre el porcentaje del empleo del sector manufacturero en el empleo total y el ingreso per cápita, que obedece al pasaje de la mano de obra del sector manufacturero al sector de servicios a medida que las economías alcanzan un mayor nivel de desarrollo. La segunda se basa en el cambio en la relación entre el empleo del sector manufacturero y el ingreso per cápita a causa del crecimiento de la productividad en este sector, las actividades de externalización y la reducción de la elasticidad ingreso de la demanda de manufacturas. El nivel del ingreso per cápita que marca el inicio de la desindustrialización en la economía también ha cambiado: en 1980, el ingreso per cápita en que la participación de las manufacturas en el producto empezaba a disminuir ascendía a 21.000 dólares, cifra que se redujo a 10.000 dólares en 1990. Una tercera explicación radica en el fenómeno de la enfermedad holandesa en países donde hubo un auge de la exportación de bienes primarios. El autor señala que los países que experimentaron desindustrialización fueron aquellos que no tuvieron superávit en la cuenta comercial de manufacturas. Entre ellos identificó a la Argentina, el Brasil, Chile y el Uruguay como países que sufrieron desindustrialización después de la introducción de reformas económicas, que se tradujeron en cuantiosos déficits en la balanza comercial de productos manufacturados, la contracción relativa del empleo en este sector y el lento crecimiento económico, fenómenos que el autor calificó de destrucción no creativa.

Frenkel y Rapetti (2012) argumentan que las entradas de capital a la región desde los años noventa pueden conducir a la apreciación del tipo de cambio y, por tanto, a la contracción de los

\footnotetext{
3 Sobre las experiencias de desindustrialización y posterior reindustrialización en la India y el Japón véanse, respectivamente, Clingingsmith y Williamson (2005) y Tahara y Uemura (2013).
} 
sectores de bienes transables, socavando así el crecimiento económico. Los autores presentaron datos que mostraban el aumento de los costos de la mano de obra (en dólares) en varios países de la región en el período 2002-2003. Esto implicaba problemas de rentabilidad y pérdida de competitividad de los bienes transables. Al analizar las causas del incremento de los costos unitarios de la mano de obra, encontraron que estas eran, en orden de importancia, la apreciación cambiaria a partir de 2002, el aumento de los salarios reales y la pérdida de productividad. Los autores concluyeron que la apreciación cambiaria resultante de las entradas de capital puede incidir de manera negativa en el valor agregado y del empleo del sector manufacturero, y por tanto en el crecimiento económico.

Brady, Kaya y Gereffi (2008) examinaron diversos canales relacionados con la ventaja comparativa, el marco institucional y la teoría de la dependencia, a través de los cuales los países de América Latina pueden haber experimentado desindustrialización. Usaron datos quinquenales comprendidos en el período 1980-2006 de 20 países de la región para estimar ecuaciones con el porcentaje del sector manufacturero en el empleo total como variable dependiente. En la estimación con variables relacionadas con la ventaja comparativa, solo los coeficientes de las tasas de inflación y de inversión fueron significativos y positivos. Estas variables también mostraron coeficientes significativos y del mismo signo en estimaciones subsecuentes. En las ecuaciones con indicadores de tipo institucional, el coeficiente de la variable cualitativa que representaba la membresía en el Programa Centroamericano de Integración Económica fue significativo y positivo, de manera que este esquema de integración constituyó un medio para combatir la desindustrialización. Por el contrario, el coeficiente de la variable que representaba la membresía en el Mercado Común del Sur (MERCOSUR) resultó negativo. En esta estimación, el gasto militar como porcentaje del producto presentó un coeficiente negativo. Los resultados con las variables de la teoría de la dependencia mostraron que la importación de bienes manufacturados tenía efectos negativos en el empleo en el sector, al igual que la inversión extranjera como porcentaje del PIB y las exportaciones de minerales en bruto como porcentaje de las exportaciones totales, mientras que el coeficiente de la razón de las exportaciones a los Estados Unidos y las exportaciones totales fue positivo.

En Colombia, la participación del sector industrial en el producto disminuyó del 25\% en 1975 al $22 \%$ a mediados de los años ochenta y al $12 \%$ en 2014. De acuerdo con Clavijo, Vera y Fandinho (2014), las causas de este proceso incluyen el aumento sustancial de las exportaciones de minerales y petróleo - y la consecuente apreciación del tipo de cambio - y la modernización económica, medida como el aumento del ingreso per cápita y de la participación del sector de servicios en el PIB. Los autores estimaron ecuaciones de cointegración para cada una de las hipótesis y hallaron que el aumento de 1 punto porcentual en la razón de la exportación de minerales en las exportaciones totales daba lugar a una reducción de la participación de la industria manufacturera en el producto de 0,4 puntos porcentuales, mientras que la apreciación cambiaria en 1 punto porcentual provocaba una contracción de 0,12 puntos. Este resultado apoyaba la hipótesis de que la desindustrialización era resultado de la apreciación cambiaria, en un contexto de enfermedad holandesa ${ }^{4}$. Los resultados de la hipótesis de modernización económica indicaron que no existía un vector de cointegración entre las variables.

De la reseña anterior se desprende que la desindustrialización es un fenómeno prevaleciente en países de distintos niveles de desarrollo y que no es posible identificar una causa única. Su origen depende de la manera en que la apreciación cambiaria, el aumento de la productividad del sector manufacturero, la reducción de la inversión y la liberalización comercial inciden en la capacidad productiva del país en cuestión.

\footnotetext{
4 Sobre la base de datos de varios países de la región, Salama (2012) también argumentó que la causa de la desindustrialización radica en la enfermedad holandesa.
} 


\section{Datos}

Los datos utilizados en este trabajo se basan en los Indicadores del Desarrollo Mundial del Banco Mundial, excepto la serie del tipo de cambio real que se basó en datos de la Comisión Económica para América Latina y el Caribe (CEPAL). Como primer paso del análisis empírico, se llevaron a cabo pruebas de raíces unitarias de todas las variables incluidas en el trabajo mediante la prueba de Dickey-Fuller aumentada, cuyos resultados se muestran en el anexo A1. En todos los casos estos estadísticos indicaron que las variables no eran estacionarias al nivel del $1 \%$, excepto las variables tasa de crecimiento económico (GDPgrowth) y tasa de inversión privada (Ipri) que lo eran al nivel del $10 \%$. Al aplicar estas pruebas a las primeras diferencias de las variables se comprobó que eran estacionarias, por lo que se deduce que todas las series son integradas de orden uno. En el cuadro 1 se presentan los valores medios, las desviaciones estándar y las definiciones de las variables incluidas en este trabajo.

Cuadro 1

Definición, valores anuales medios y desviaciones estándar de las variables

\begin{tabular}{lcc}
\hline Variable & Valor medio & Desviación estándar \\
\hline Agric, participación del sector agropecuario en el PIB & 12,53 & 2,38 \\
\hline Manu, participación del sector manufacturero en el PIB & 3,68 & 3,25 \\
\hline Agric+Manu, participación de los bienes transables en el PIB & 3,63 & 3,25 \\
\hline Remy, monto de remesas como porcentaje del PIB & 13,81 & 3,15 \\
\hline Gdpgrowth, tasa de crecimiento económico & 3,16 & 2,29 \\
\hline RER, tipo de cambio real & 107,21 & 13,10 \\
\hline Imports, importaciones totales como porcentaje del PIB & 39,33 & 5,58 \\
\hline Exports, exportaciones totales como porcentaje del PIB & 23,52 & 3,61 \\
\hline ExpCAy, exportaciones hacia Centroamérica como porcentaje del PIB & 5,72 & 1,13 \\
\hline Importconsumondy, importación de bienes de consumo no duradero como porcentaje del PIB & 9,07 & 2,29 \\
\hline Ipri, tasa de inversión privada & 12,97 & 1,11 \\
\hline Grosssavings, tasa de ahorro nacional & 13,80 & 2,63 \\
\hline Serv, participación del sector de servicios en el PIB & 58,27 & 2,24 \\
\hline TB, balanza en la cuenta comercial como porcentaje del PIB & 16,23 & 3,09 \\
\hline Arancelpromedio, arancel medio en porcentajes & 8,66 & 3,58 \\
\hline Indicegeneral, índice general de reformas & 0,57 & 0,07 \\
\hline
\end{tabular}

Fuente: Elaboración propia, sobre la base de Banco Mundial, Indicadores del Desarrollo Mundial.

Nota: PIB: Producto interno bruto.

\section{Análisis de las posibles causas de la desindustrialización en El Salvador}

En el gráfico 1 se muestra la trayectoria de la participación del valor agregado de los sectores manufacturero y agrícola en el PIB en el período 1990-2013 en El Salvador. La tendencia declinante de estas variables pone en evidencia el proceso de desindustrialización y de contracción relativa de los sectores de bienes transables. 
Gráfico 1

El Salvador: participación del valor agregado de los sectores manufacturero y agrícola en el PIB, 1990-2013

(En porcentajes)

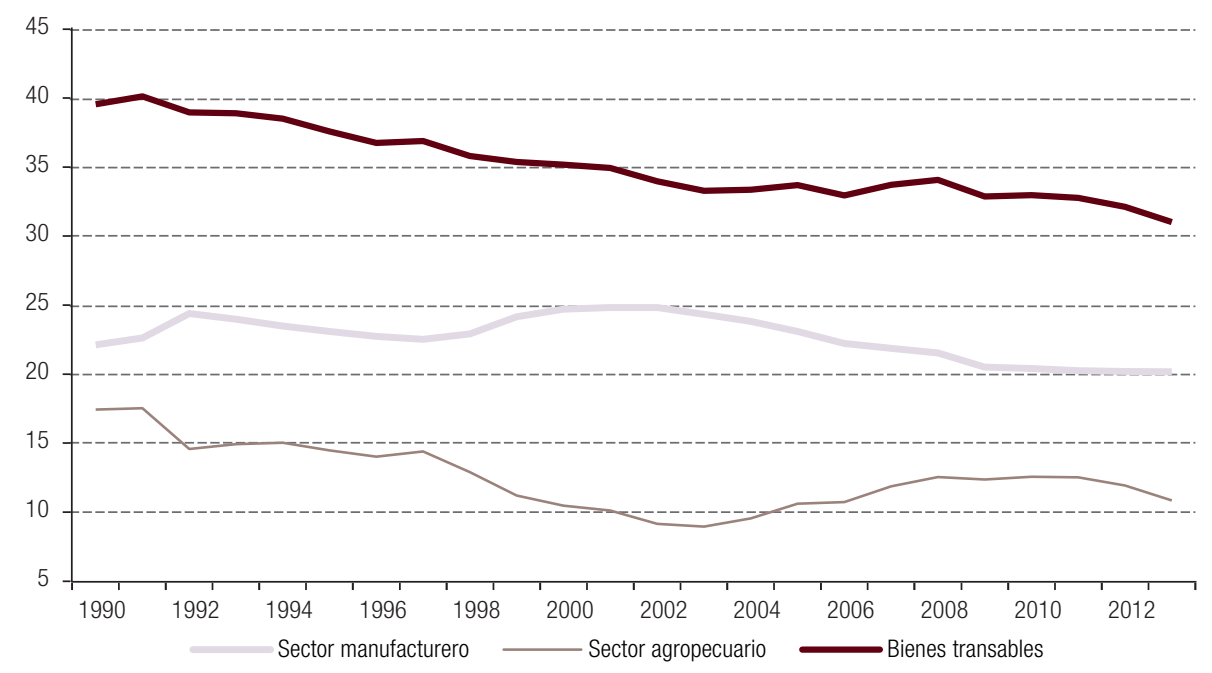

Fuente: Elaboración propia, sobre la base de Banco Mundial, Indicadores del Desarrollo Mundial. Nota: PIB: Producto interno bruto.

\section{Apreciación cambiaria}

Como primer paso para explicar esta tendencia se examina el fenómeno de la enfermedad holandesa, que puede derivar del auge de las remesas, cuya participación en el PIB aumentó del 7,63\% en 1990 al 16,37\% en 2013, con un valor máximo del 18,77\% en 2006. Este ingreso sustancial de recursos podría dar lugar al aumento del índice de precios y, por tanto, a la apreciación del tipo de cambio. Esto significaría que los bienes transables perderían competitividad y su participación en el producto declinaría. Varios autores encontraron evidencia de que las remesas conducen a la apreciación del tipo de cambio (Lartey, Mandelman y Acosta, 2008; Díaz González, 2009). Cabe destacar que, antes de la dolarización de la economía en 2001, la relación entre el tipo de cambio real (RER) y las remesas como porcentaje del PIB (Remy) tenía una pendiente negativa (véase el gráfico 2), mientras que en el período posterior a 2000 la pendiente se volvió positiva (véase el gráfico 3).

Antes de la dolarización, las remesas tendían a revaluar el tipo de cambio, como era de esperar, mientras que después de esa medida contribuyen a devaluarlo. La depreciación real de la moneda salvadoreña (el dólar) obedece a que los países vecinos miembros del Programa Centroamericano de Integración Económica, con los cuales El Salvador tiene fuertes vínculos comerciales, suelen presentar tasas de inflación más altas que las de El Salvador después de 2001, dando lugar así a un aumento de la competitividad salvadoreña en sus relaciones comerciales bilaterales con estos países. Las exportaciones salvadoreñas al resto de Centroamérica como porcentaje de las exportaciones totales ascendían a alrededor del 20\% en los años noventa, pero este porcentaje empezó a crecer en 2003 hasta alcanzar el 32,28\% en 2013. Los elevados montos de remesas recibidos por los otros países centroamericanos, excepto Costa Rica, influyen en este resultado. 


\section{Gráfico 2}

El Salvador: tipo de cambio real y remesas, 1990-2000

(Índice $2005=100$ y porcentajes del PIB)

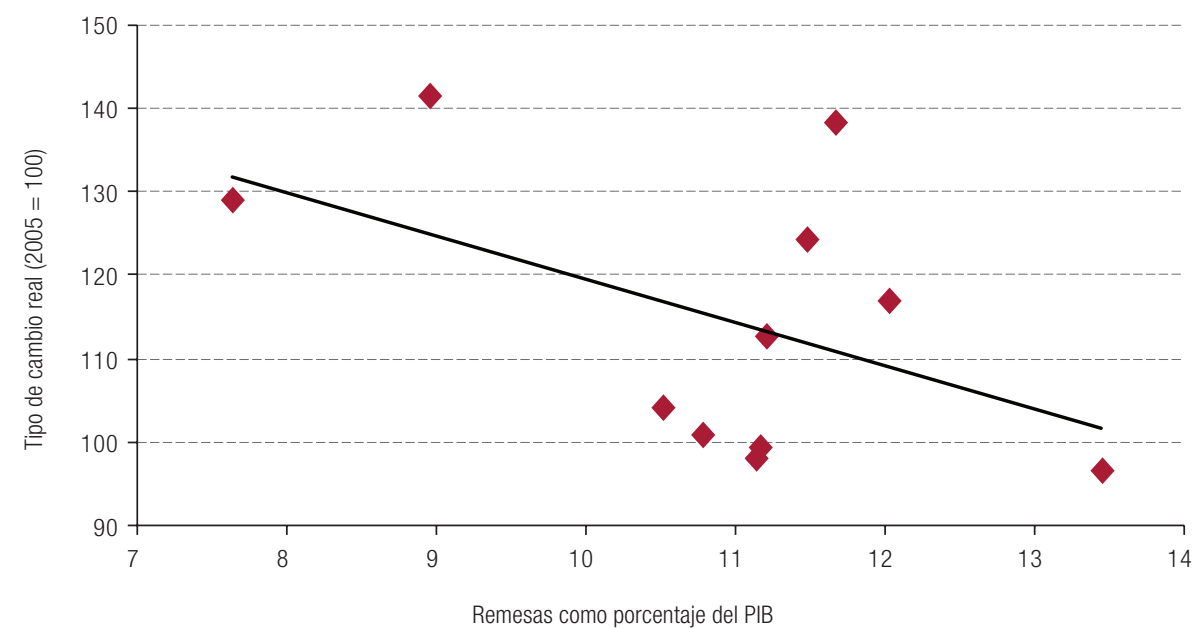

Fuente: Elaboración propia, sobre la base de Banco Mundial, Indicadores del Desarrollo Mundial. Nota: PIB: Producto interno bruto.

Gráfico 3

El Salvador: tipo de cambio real y remesas, 2001-2013

(Índice $2005=100$ y porcentajes del PIB)

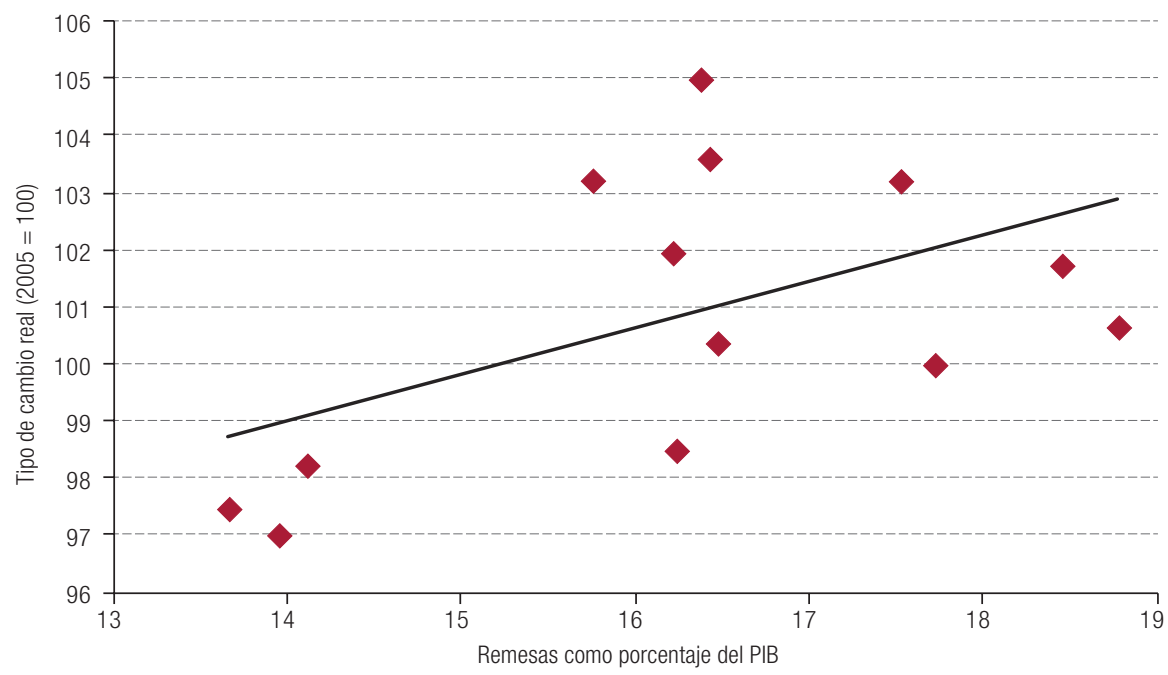

Fuente: Elaboración propia, sobre la base de Banco Mundial, Indicadores del Desarrollo Mundial.

Nota: PIB: Producto interno bruto.

Para verificar el papel de las remesas en el tipo de cambio real, se estimó una ecuación de cointegración por el método de mínimos cuadrados ordinarios completamente modificados, un procedimiento que corrige los resultados de mínimos cuadrados ordinarios al tomar en cuenta que todas las variables de un vector de cointegración son endógenas (Phillips y Hansen, 1990) ${ }^{5}$. La

5 Antes de estimar las ecuaciones de cointegración se realizaron pruebas de la existencia de vectores de cointegración entre las variables comprendidas en las diferentes ecuaciones. Los resultados de la aplicación de la metodología de la traza de Johansen indicaron que existían uno o dos vectores de cointegración en las ecuaciones presentadas en los cuadros 2, 3, 4, 5 y 6, excepto en la ecuación (12) del cuadro 6, que se estimó por mínimos cuadrados ordinarios. 
ecuación (1) del cuadro 2 expresa el tipo de cambio real (RER) como función del monto de remesas como porcentaje del PIB (Remy) y de una variable cualitativa (Cualid), que toma el valor 1 en cada año después de la dolarización y 0 antes de esta medida y se incluye en la ecuación tanto para detectar cambios en el intercepto como en el coeficiente de Remy. Se observa que todos los coeficientes son significativos, pero el R cuadrado y el estadístico de Durbin Watson son bajos. En el período previo a la dolarización, el coeficiente de Remy es negativo e indica que el crecimiento de esta variable conducía a la revaluación cambiaria. En el segundo período Remy muestra un efecto positivo en el tipo de cambio real igual a 0,7614 (8,6710-7,9096), de manera que - al contrario de lo que se esperaba - el efecto del aumento de la relación entre las remesas y el PIB era la depreciación cambiaria.

Utilizando el mismo método, se estimó una segunda ecuación, que expresa la participación del sector manufacturero en el PIB en función de Remy y Cualid (véase el cuadro 2). Se puede observar que el coeficiente de RER no es significativo en el primer período, pero sí es significativo y negativo en el segundo $(-0,7144)$. Esto indica que la depreciación cambiaria real estaba asociada de manera positiva con la desindustrialización, un resultado contrario a la explicación de la desindustrialización basada en la enfermedad holandesa.

\section{Cuadro 2}

Remesas, tipo de cambio y valor agregado del sector manufacturero, 1990-2013 (Índice $2005=100$ y porcentajes del PIB)

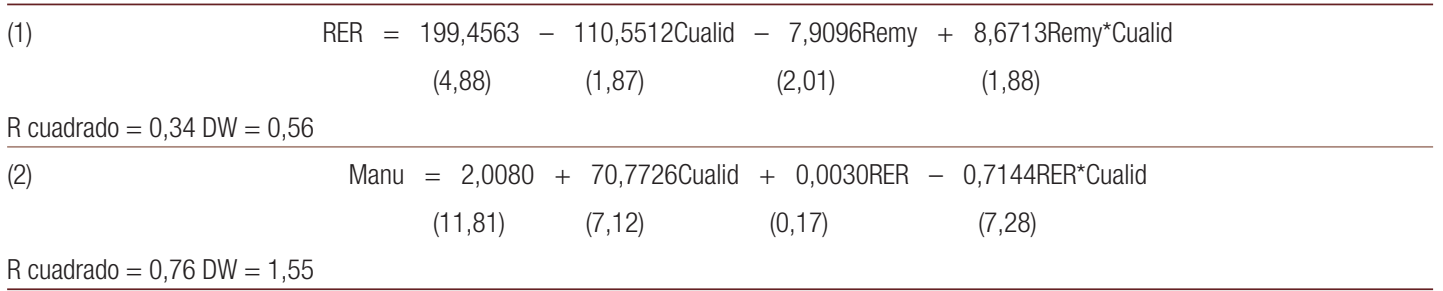

Fuente: Elaboración propia, sobre la base de Banco Mundial, Indicadores del Desarrollo Mundial.

Nota: PIB: Producto interno bruto.

Los resultados anteriores muestran que no existe el fenómeno de la enfermedad holandesa en El Salvador y que la depreciación cambiaria no ha contribuido a detener el proceso de desindustrialización. Por tanto, es necesario buscar la explicación de la desindustrialización en El Salvador en otras variables y en medidas de política económica tomadas en el pasado.

\section{Liberalización comercial}

A mediados de los años ochenta, El Salvador comenzó a aplicar una serie de medidas de política comercial que conllevaron la eliminación de restricciones cuantitativas a las importaciones y, especialmente, la rebaja de los aranceles de importación. Según los datos de Lora (2012), la media de los aranceles aplicados a las importaciones, que ascendía al 22,68\% en 1986, se redujo al 12,92\% en 1993 y al 5,8\% en $2009^{6}$. Este último valor equivalía a la mitad de los aranceles prevalecientes en los países andinos y del MERCOSUR. De acuerdo con otras fuentes, como los Indicadores del Desarrollo Mundial del Banco Mundial, el valor de los aranceles de importación de El Salvador era más bajo, de alrededor del 2\% en 2013. En los años noventa se tomaron otras medidas de liberalización económica en diversas áreas, como la financiera, tributaria, laboral y de privatización.

6 La serie de datos preparada por Lora (2012) abarca el período 1985-2009. 


\section{Importaciones y desindustrialización}

El aumento de la importación de bienes de consumo no duradero (Importconsumondy), del 6\% al 12\% del PIB entre 1990 y 2013, se relaciona con la contracción de la participación de los bienes transables en el PIB (Manu+Agric) (véase el gráfico 4).

\section{Gráfico 4}

El Salvador: producción de bienes transables e importación de bienes de consumo no duradero, 1990-2013

(En porcentajes del PIB)

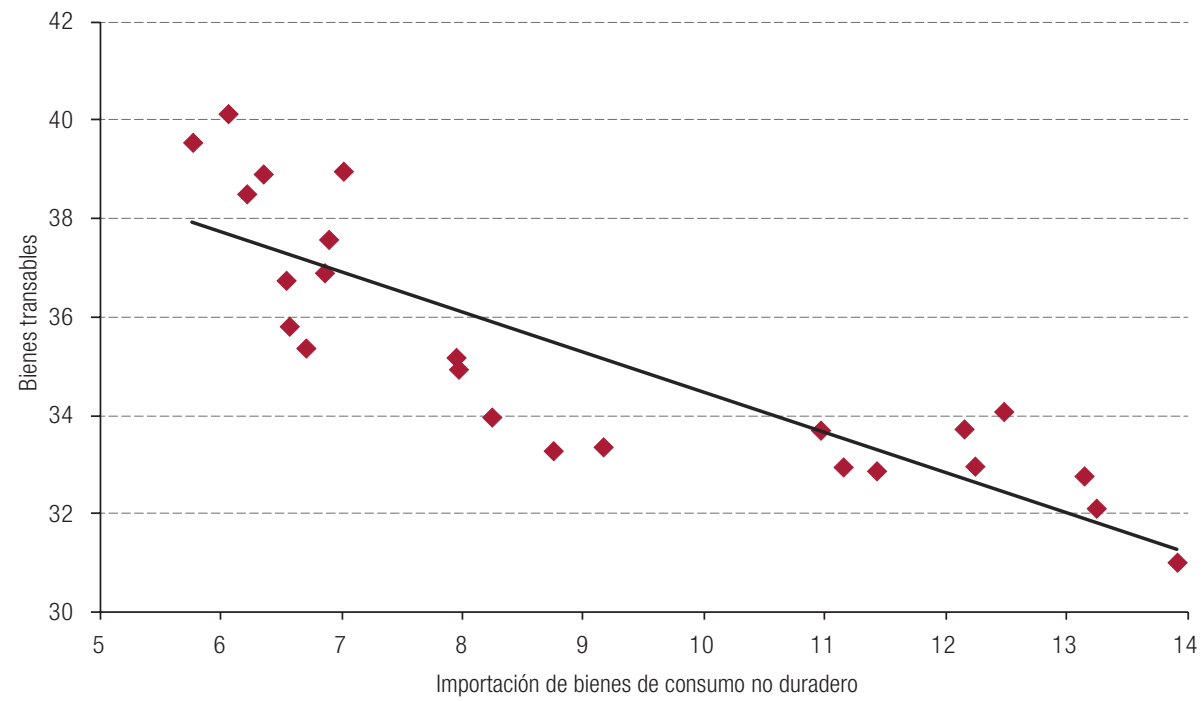

Fuente: Elaboración propia, sobre la base de Banco Mundial, Indicadores del Desarrollo Mundial.

Nota: PIB: Producto interno bruto.

Para analizar este punto se estimaron ecuaciones de cointegración con el método de mínimos cuadrados ordinarios completamente modificados, que expresaban la variable Manu en términos de Importconsumondy y otras variables. En la ecuación (3) (véase el cuadro 3) se observa que las importaciones de bienes de consumo no duradero como porcentaje del producto tienen un impacto negativo en la producción manufacturera nacional. Por su parte, las remesas tienen un efecto positivo. Esta ecuación explica el $77 \%$ de la varianza de Manu. En la ecuación (4) se incluyó la tasa de inversión privada (Ipri), que presenta un coeficiente positivo y significativo. El coeficiente de Remy solo es significativo al nivel del 14\%. Esta ecuación explica el $81 \%$ de la varianza de Manu. Las exportaciones de El Salvador a los otros países centroamericanos como porcentaje del PIB (ExpCAy) se incluyeron como variable independiente en la ecuación (5). El coeficiente significativo y positivo indica que los flujos comerciales regionales protegen contra la desindustrialización. Esto se debe a que el comercio intrarregional centroamericano está constituido en su mayor parte por el intercambio de bienes manufacturados. De hecho, Rodrik (2015) señala que en los países cuyas exportaciones de manufacturas superaban el $75 \%$ del total de exportaciones no hubo desindustrialización. 


\section{Cuadro 3}

El Salvador: desindustrialización e importaciones de bienes de consumo no duradero, 1990-2013

(En porcentajes del PIB)

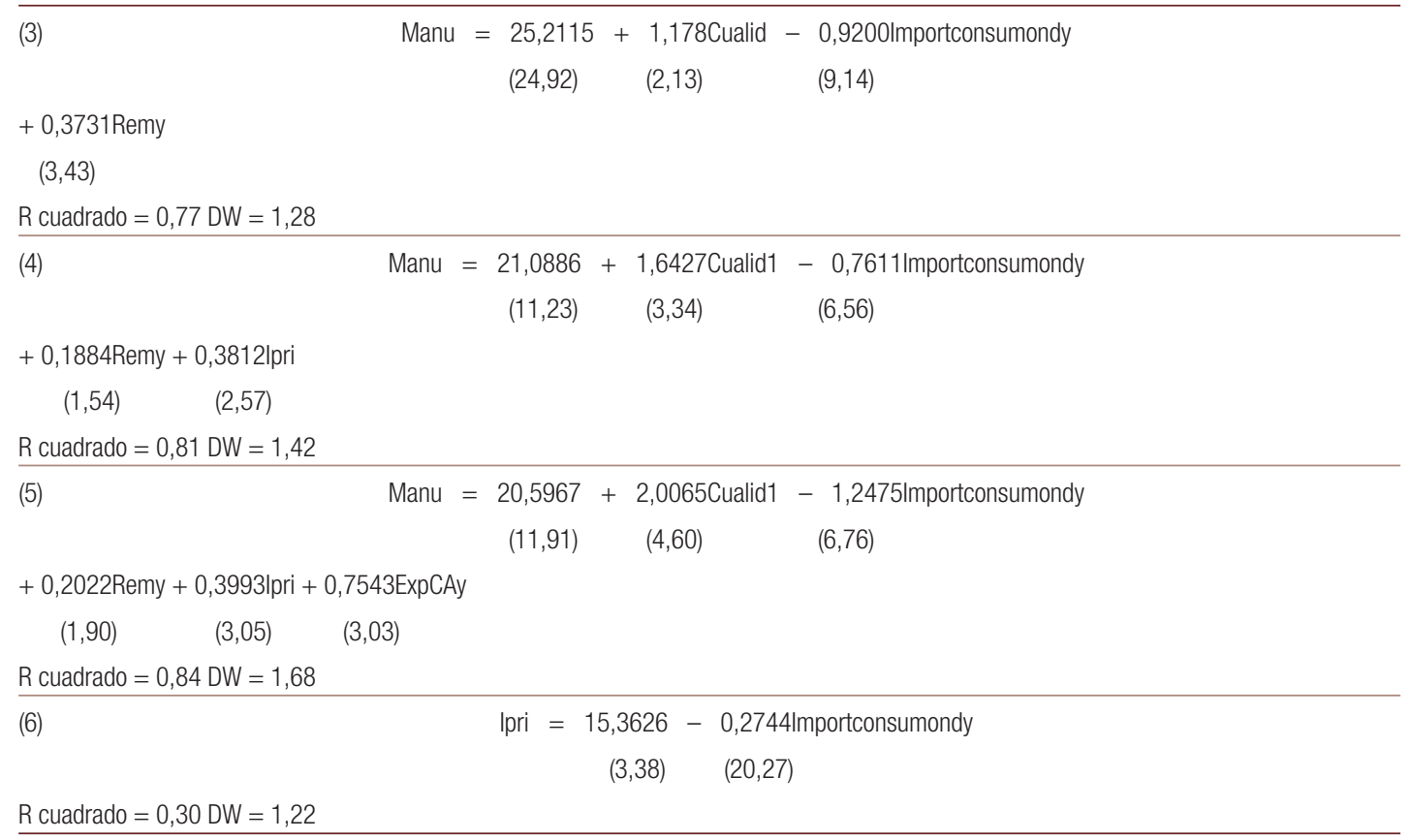

Fuente: Elaboración propia, sobre la base de Banco Mundial, Indicadores del Desarrollo Mundial.

Nota: PIB: Producto interno bruto.

En las ecuaciones (4) y (5) del cuadro 3 se observa que la inversión privada tiene un efecto positivo en la participación de la producción manufacturera en el PIB. Sin embargo, como se aprecia en la ecuación (6) del cuadro 3, la variable Importconsumondy tiene un impacto negativo en la tasa de inversión privada. Es decir, la importación masiva de bienes de consumo desplaza la inversión privada. Este resultado se ha observado en varios países ${ }^{7}$. Así, además de desindustrialización y desagriculturización económica, El Salvador sufre un proceso de descapitalización, ya que la apertura extrema de la economía inhibe la movilización de capital productivo adicional. De hecho, desde mediados de los años noventa las tasas de inversión, privada y total, son más bajas que en las décadas de 1960 y 1970.

\section{Reducción del arancel externo}

La reducción del arancel externo dio lugar al aumento desmedido de las importaciones de bienes de consumo. Por ello, se estimó una ecuación de cointegración con datos de 1990-2009 que expresaba la participación del valor agregado de los bienes transables (Manu+Agric) en el PIB en términos del

7 En una muestra de países en desarrollo y desarrollados, Tregenna (2011) encontró que la desindustrialización estaba acompañada por una merma de la inversión. Bennell (1998) presentó evidencia de que la inversión privada en los países de África Subsahariana se redujo después de la liberalización económica en los años ochenta. Este autor cita las conclusiones de un estudio de la IFC (1995) sobre la inversión privada en estos países y afirma que el tan esperado renacer del sector privado después de la liberalización económica no se ha materializado en África Subsahariana. Aunque se notan señales de dinamismo en la pequeña agricultura y el sector informal, la respuesta del sector formal todavía no se ha hecho sentir en la mayoría de los países. Noorbakhsh y Paloni (1999) presentan evidencia de desindustrialización en los países de África Subsahariana en el contexto de programas de ajuste estructural. Véanse otras evidencias de desindustrialización en África Subsahariana en Jalilian y Weiss (2000). 
valor medio del arancel, tomado de Lora (2012) (véase la ecuación (7) del cuadro 4). El coeficiente del arancel medio es significativo y positivo. Esto indica que el incremento de la protección conduciría a un aumento de la participación relativa de los bienes transables, de manera que si el arancel alcanzara la media de América Latina del 12\%, un aumento de 7 puntos porcentuales, la participación del valor agregado de los bienes transables en el PIB aumentaría 2,8 puntos porcentuales. Cabe recalcar que el arancel externo y la variable cualitativa que representa la entrada en vigencia de la dolarización explican el 92\% de la varianza de la participación de los bienes transables en el PIB.

Se estimó una ecuación de cointegración que expresaba la tasa de crecimiento económico anual (GDPgrowth) en términos de participación del sector manufacturero en el PIB (Manu) y del arancel medio, que se presenta en el cuadro 4 como la ecuación (8). Los coeficientes de Manu y del arancel son positivos y significativos, de lo que se desprende que si el arancel aumentara 7 puntos porcentuales el crecimiento económico aumentaría cerca de 2 puntos $(7 \times 0,283)$. Este resultado cobra especial importancia ante los intentos fallidos de dinamizar la economía en las dos últimas décadas.

Cuadro 4

El Salvador: arancel externo, desindustrialización y crecimiento económico, 1990-2009

(En porcentajes del PIB)

(7)

Manu + Agric $=33,4477-2,5392$ Cualid + 0,3974Arancelpromedio

$(97,78) \quad(12,31) \quad(12,21)$

R cuadrado $=0,92 \mathrm{DW}=2,90$

(8) Gdpgrowth $=-15,3940-1,3328$ Cualid + 0,7268Manu +

$(2,02) \quad(1,54) \quad(2,26)$

0,2830Arancelpromedio

$(2,08)$

R cuadrado $=0,48 \mathrm{DW}=1,13$

Fuente: Elaboración propia, sobre la base de Banco Mundial, Indicadores del Desarrollo Mundial.

Nota: PIB: Producto interno bruto.

\section{5. Índice general de reformas}

Lora (2012) computó un índice general de reformas estructurales para cada país de América Latina y el Caribe, que varía de 0 a 1 según su cobertura y profundidad. En el caso de El Salvador, este índice general aumentó de 0,43 en 1990 a 0,64 en 2009. Se estimó una ecuación de cointegración (véase la ecuación (9) del cuadro 5) que expresa la participación de los bienes transables en el PIB en términos del índice general de reformas. Los resultados indican que el "avance" en las reformas y la variable Cualid explican el 94\% de la varianza de la merma de la participación de los bienes transables en el producto. De hecho, el aumento actual del índice general de reformas en 0,21 puntos porcentuales $(0,64-0,43)$ se relaciona con la pérdida de 6,35 puntos porcentuales $(30,2406 \times 0,21)$ en la participación de los bienes transables en el PIB, cifra cercana al valor real de 6,68 puntos porcentuales correspondiente a la desindustrialización y desagriculturización entre 1990 y 2009 (39,55 - 32,87) (véase el gráfico 5). 


\section{Gráfico 5}

El Salvador: participación de bienes transables en el PIB e índice general de reformas

(En porcentajes del PIB)

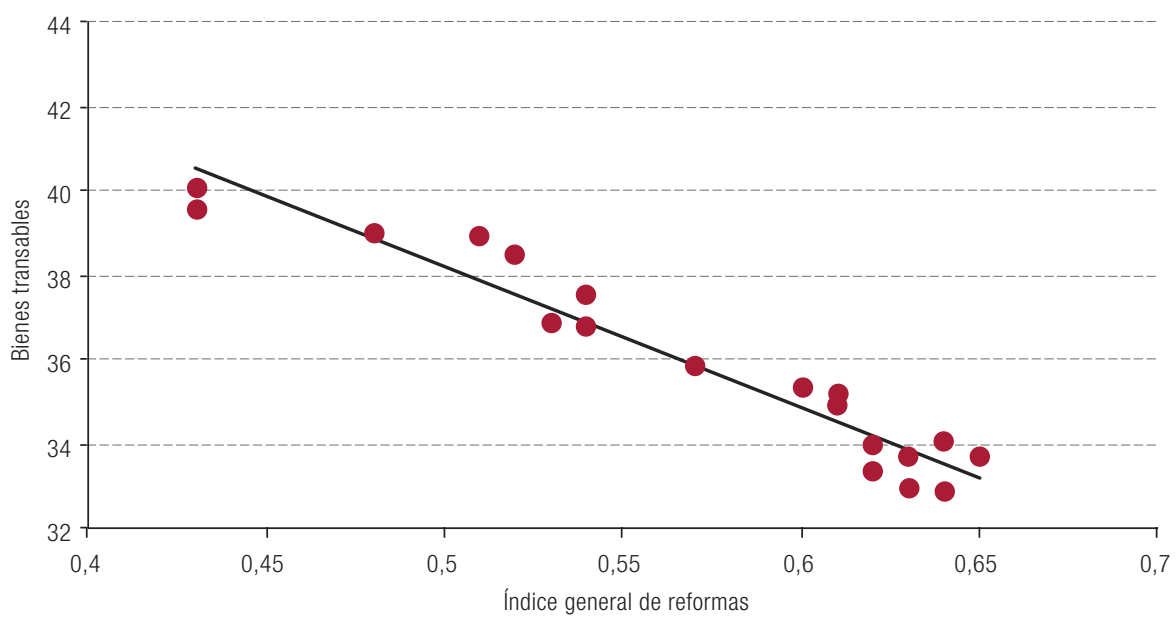

Fuente: Elaboración propia, sobre la base de Banco Mundial, Indicadores del Desarrollo Mundial.

Nota: PIB: Producto interno bruto.

En la ecuación (10) del cuadro 5 se observa que el aumento del índice general de reformas tiene un impacto negativo en el crecimiento económico, de manera que el "progreso" en esta área representa una pérdida de crecimiento económico de casi 4 puntos porcentuales $(0,21 \times 18,77)$. A partir de la ecuación (10) se calculó la pérdida de crecimiento económico anual a raíz de las reformas, suponiendo que el índice general de reformas hubiese permanecido en su valor de 1990 en todo el período. Esta pérdida se suma al valor real de crecimiento económico (GDPgrowth) para obtener la serie de crecimiento económico bajo el supuesto de que no hubiera habido reformas (CRECSINREF) (véase el gráfico 6). La diferencia entre las dos líneas del gráfico 6 es el costo (parcial) de las reformas.

\section{Gráfico 6}

El Salvador: tasas de crecimiento económico real e hipotético bajo el supuesto de que las reformas no se hubiesen llevado a cabo, 1990-2009

(En porcentajes del PIB)

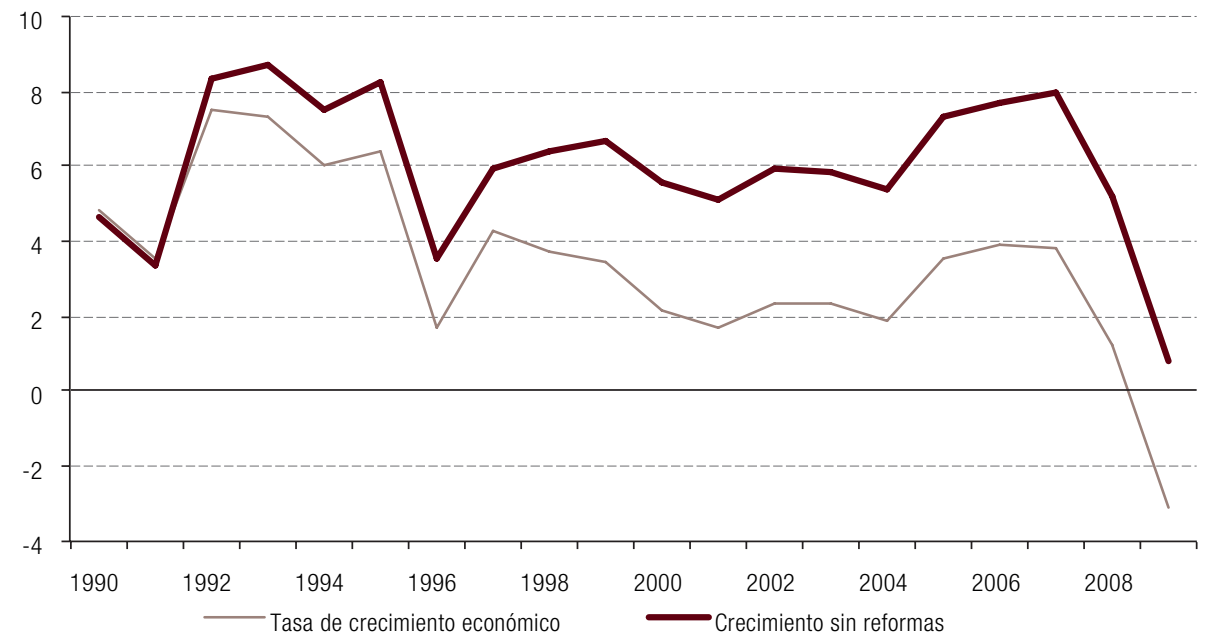

Fuente: Elaboración propia, sobre la base de Banco Mundial, Indicadores del Desarrollo Mundial. Nota: PIB: Producto interno bruto. 


\section{Cuadro 5}

El Salvador: índice general de reformas y desindustrialización, desagriculturización y crecimiento económico, 1990-2009

(En porcentajes del PIB)

(9) Manu + Agric $=\begin{array}{ccc}5,4286 & -0,8441 \text { Cualid }- & 30,2406 \text { Indicegeneral } \\ (26,57) & (1,84) & (8,0540)\end{array}$

R cuadrado $=0,94 \mathrm{DW}=1,40$

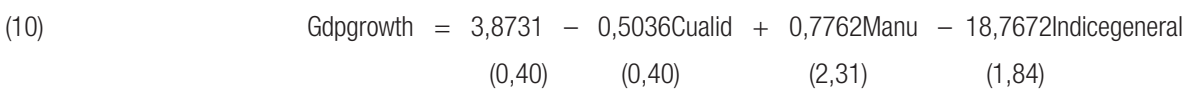

R cuadrado $=0,43 \mathrm{DW}=1,13$

Fuente: Elaboración propia, sobre la base de Banco Mundial, Indicadores del Desarrollo Mundial.

Nota: PIB: Producto interno bruto.

\section{Déficit en la cuenta comercial de la balanza de pagos}

Otro fenómeno de especial importancia en las últimas tres décadas es el alto déficit en la cuenta comercial de la balanza de pagos (TB), que aumentó del 12,67\% del PIB en 1990 hasta alcanzar el 22,82\% en 2008 y el 19,41\% en 2013. El crecimiento de este déficit se relaciona estrechamente con la contracción de la participación de los bienes transables en el producto (Manu+Agric) (véase el gráfico 7).

\section{Gráfico 7}

El Salvador: déficit de la cuenta comercial de la balanza de pagos y participación de los bienes transables en el PIB, 1990-2013

(En porcentajes del PIB)

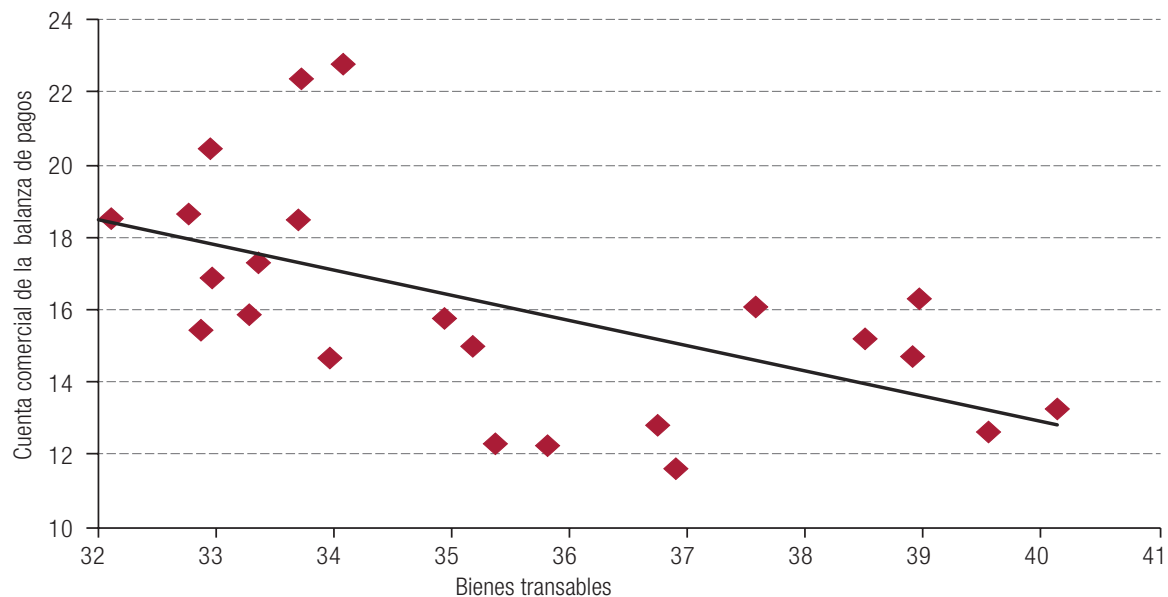

Fuente: Elaboración propia, sobre la base de Banco Mundial, Indicadores del Desarrollo Mundial. Nota: PIB: Producto interno bruto.

Una consecuencia del alto déficit comercial es la reducción del ahorro nacional a valores sumamente bajos en los últimos años, de alrededor del 8\% (véase el gráfico 8). 


\section{Gráfico 8}

El Salvador: tasa de ahorro nacional y déficit de la cuenta comercial de la balanza de pagos

(En porcentajes del PIB)

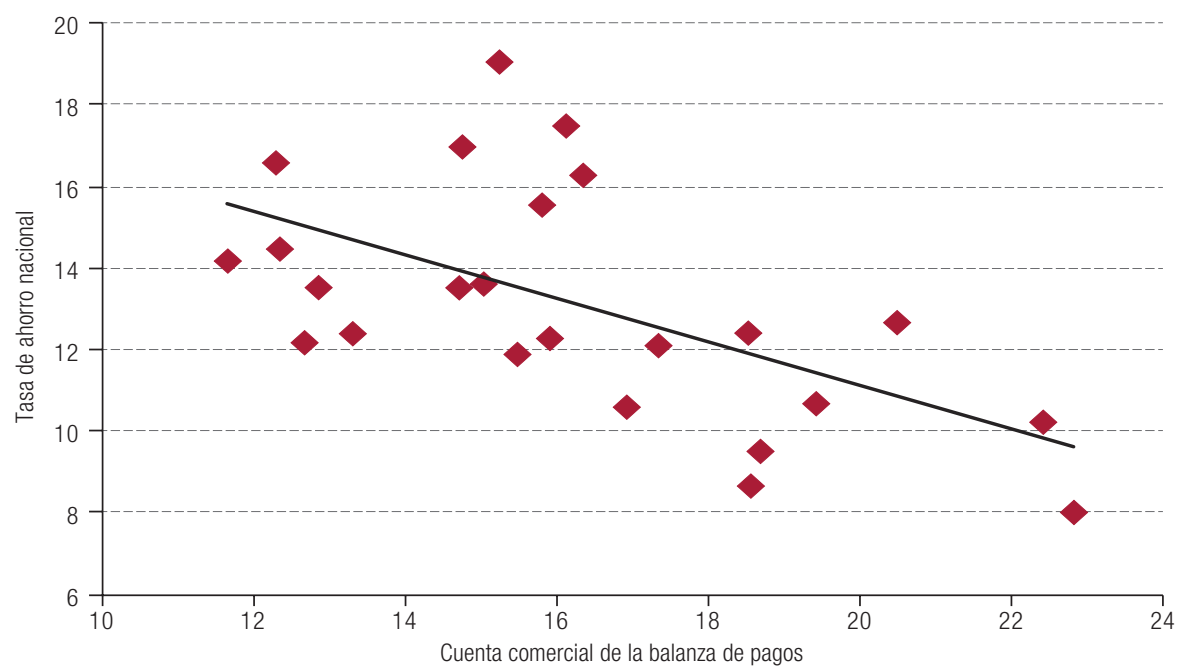

Fuente: Elaboración propia, sobre la base de Banco Mundial, Indicadores del Desarrollo Mundial.

Nota: PIB: Producto interno bruto.

La explicación reside en que, a medida que el déficit comercial aumenta, se requieren mayores montos de ahorro externo para cubrir el déficit en cuenta corriente, lo que desplaza el ahorro nacional ${ }^{8}$. Esto se constata en la estimación de la ecuación (11) del cuadro 6, que expresa la tasa de ahorro nacional en términos de Manu, Gdpgrowth y TB. Los resultados muestran que esta última variable tiene un coeficiente negativo y significativo, que evidencia el papel negativo del déficit comercial sobre el ahorro.

La disminución del ahorro nacional conlleva la contracción de la inversión privada, que constituye otra fuente de estancamiento de la producción de bienes transables. Esto fomenta aún más el deterioro del déficit comercial, dando lugar a un proceso acumulativo de reducción del arancel externo, desindustrialización, deterioro de las cuentas externas, reducción del ahorro nacional y de la inversión, incremento de la desindustrialización y así sucesivamente.

El origen del proceso de desindustrialización y descapitalización se puede atribuir al proceso de reformas, pues existe una relación estrecha entre el índice general de reformas y el déficit en la cuenta comercial (véase el gráfico 9). Lawrence y Edwards (2013) presentaron evidencia de que en Alemania, Italia y el Japón, países con altos superávits en sus cuentas comerciales de manufacturas, la desindustrialización (medida como el porcentaje de mano de obra empleada en el sector manufacturero dentro del empleo total) no es tan acentuada como en los otros países desarrollados.

\footnotetext{
8 Prasad, Rajan y Subramanian (2007) presentaron evidencia de que el ahorro externo tiene una relación negativa con el ahorro nacional y señalaron la importancia de reducir el déficit en la cuenta comercial.
} 


\section{Gráfico 9}

El Salvador: déficit de la cuenta comercial de la balanza de pagos e índice general de reformas, 1990-2009

(En porcentajes del PIB y valor del índice de reformas (entre 0 y 1))

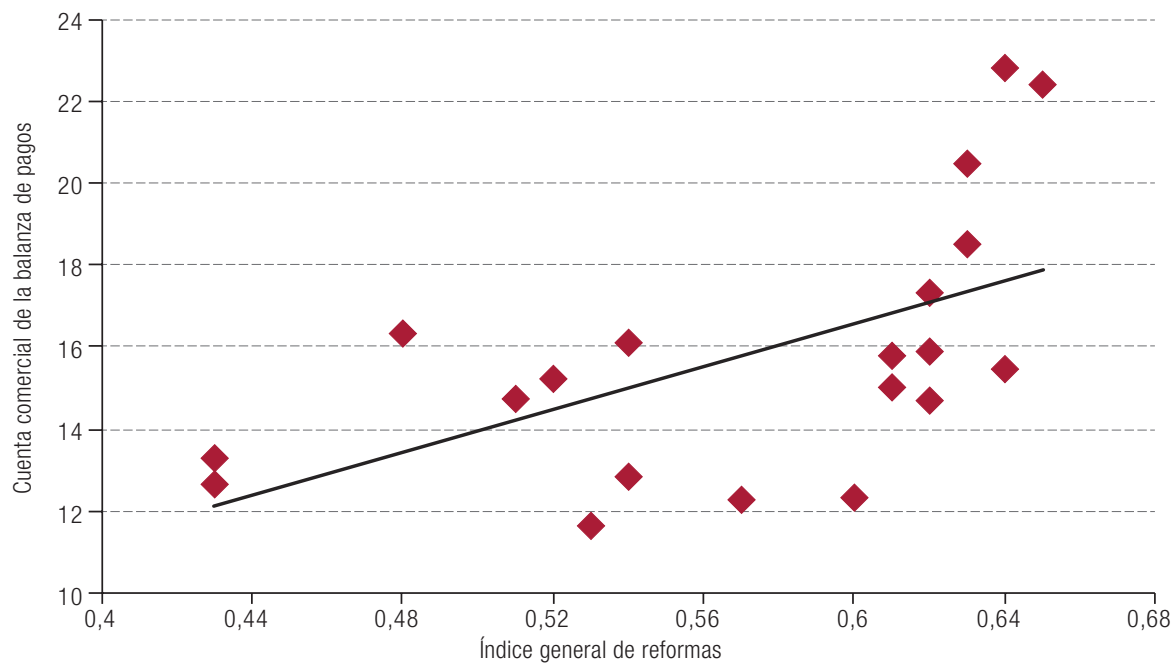

Fuente: Elaboración propia, sobre la base de Banco Mundial, Indicadores del Desarrollo Mundial.

Nota: PIB: Producto interno bruto.

\section{Sector de servicios y crecimiento económico}

A medida que se implementaron las reformas, el debilitamiento de los sectores de bienes transables estuvo acompañado por el incremento de la participación del sector de servicios en el PIB, que aumentó del 55,32\% en 1990 al 62,20\% en 2013 (véase el gráfico 10). Como se puede apreciar al estimar por medio de mínimos cuadrados ordinarios una ecuación que expresa la tasa de crecimiento económico en términos de inversión privada y participación del sector servicios en el PIB, esto representa un freno al crecimiento económico (véase la ecuación (12) del cuadro 6).

\section{Gráfico 10}

El Salvador: participación del sector de servicios en el producto e índice general de reformas, 1990-2009

(En porcentajes del PIB y valor del índice de reformas (entre 0 y 1))

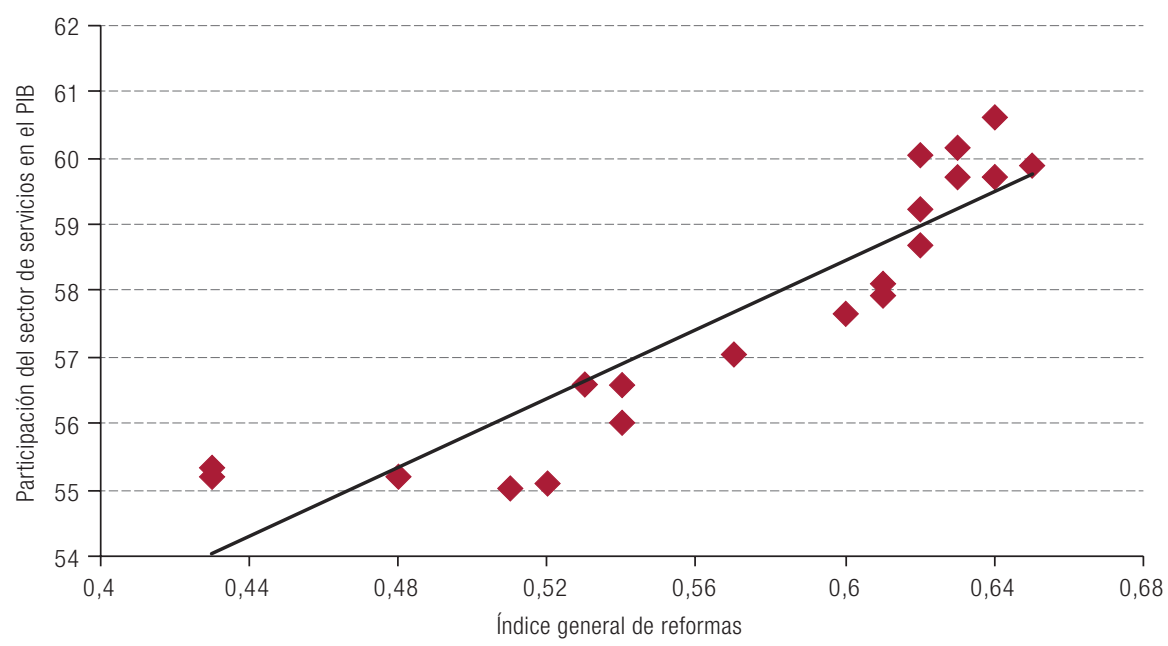

Fuente: Elaboración propia, sobre la base de Banco Mundial, Indicadores del Desarrollo Mundial. Nota: PIB: Producto interno bruto. 


\section{Cuadro 6}

El Salvador: participación en el producto de los sectores manufacturero y de servicios y ahorro nacional y crecimiento económico

(En porcentajes del PIB)

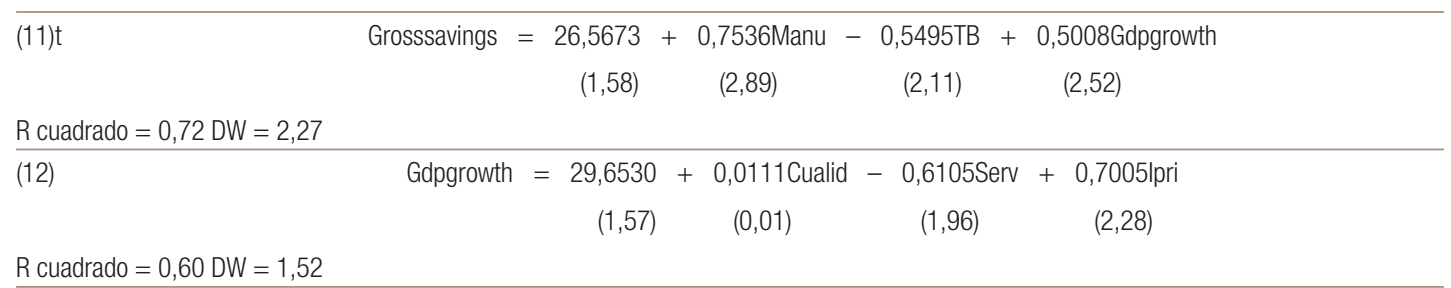

Fuente: Elaboración propia, sobre la base de Banco Mundial, Indicadores del Desarrollo Mundial.

Nota: PIB: Producto interno bruto.

Los resultados indican que el coeficiente de la variable Serv es negativo y significativo, de manera que un aumento de 1 punto porcentual de la participación de este sector en el producto conduciría a una merma del crecimiento del PIB de 0,50 puntos. Si bien el coeficiente de la tasa de inversión privada es positivo y significativo, esta variable ha disminuido constantemente desde mediados de los años noventa, de manera que no se podría esperar que pueda contrarrestar el impacto negativo de Serv. La disyuntiva es que el sector de mayor dimensión en la economía tiene un impacto negativo en el crecimiento económico (véase el gráfico 11), mientras que el sector que impulsa el crecimiento se contrae. Esto hace prever la continuación del estancamiento económico en El Salvador, sin que al menos se restituya la debida protección a los bienes transables.

\section{Gráfico 11}

El Salvador: crecimiento económico y participación del sector de servicios en el PIB, 1990-2013 (En porcentajes del PIB)

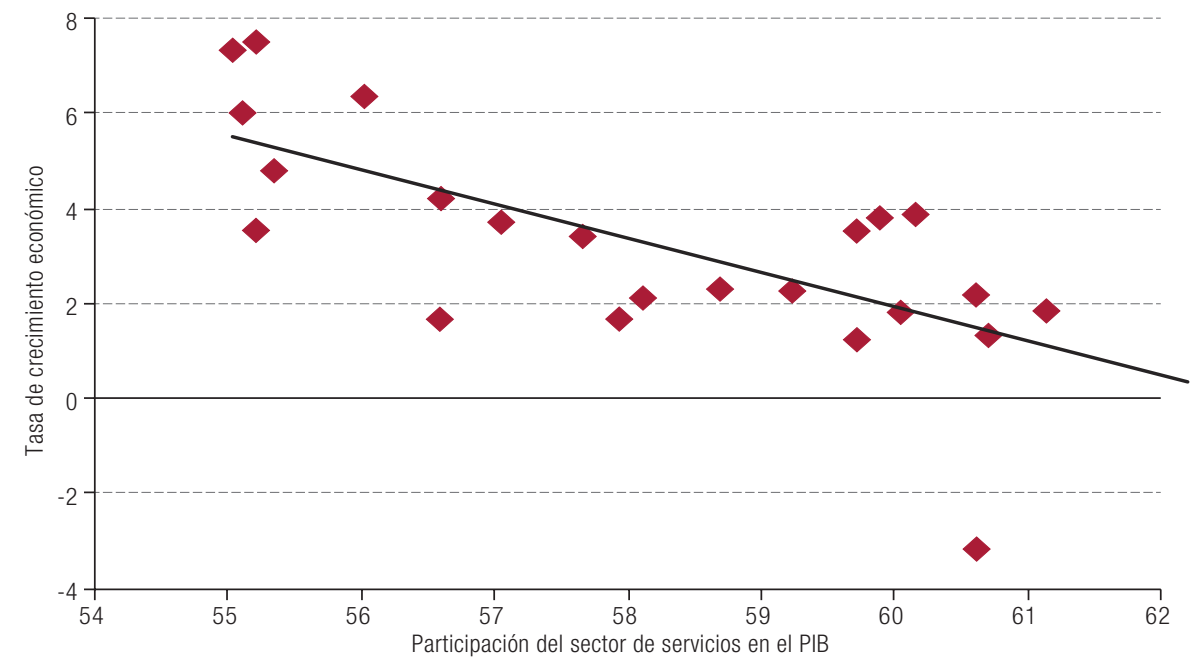

Fuente: Elaboración propia, sobre la base de Banco Mundial, Indicadores del Desarrollo Mundial Nota: PIB: Producto interno bruto.

\section{Cláusulas de salvaguarda y libre comercio}

La Organización Mundial del Comercio (OMC) reconoce el derecho de los países miembros a solicitar la introducción de medidas restrictivas de las importaciones en situaciones justificadas. La introducción de estas medidas, como el aumento temporal de las tarifas arancelarias y las acciones restrictivas de antidumping, es una práctica frecuente en el comercio mundial. Sobre la base de datos del período 
1980-1998 relativos a Australia, el Canadá, los Estados Unidos y los países de la Unión Europea, Knetter y Prusa (2003) encontraron que la depreciación de la moneda del país exportador en una desviación estándar daba lugar a un aumento del 33\% de los casos de antidumping demandados por el país importador, mientras que la reducción del PIB del país importador conducía a que este aumentara sus acciones de antidumping un $23 \%$.

Por su parte, Bown y Crowley (2013) estimaron ecuaciones para identificar las variables asociadas con la adopción de medidas proteccionistas en Australia, el Canadá, los Estados Unidos, la República de Corea y países de la Unión Europea en el período 1988-2010. Los autores encontraron que alrededor del $5 \%$ de los bienes importados a esos países eran objeto de medidas proteccionistas temporales en 2010. Una de las variables determinantes de este comportamiento fue la apreciación del tipo de cambio bilateral del país importador, que tuvo importantes repercusiones en la implementación de estas medidas en todos los países, excepto Australia. Una apreciación del $4 \%$ del tipo de cambio en el país importador daba lugar a aumentos de entre el $60 \%$ y el $90 \%$ de los bienes sujetos a protección. La reducción de la tasa de crecimiento económico también motivó la construcción de barreras a las importaciones en todos los países, excepto el Canadá. A modo de ejemplo, la contracción del crecimiento económico de Australia del 3,3\% al 0,7\% se asoció con un aumento del $40 \%$ en las medidas de restricciones antidumping adoptadas por este país.

Kee, Neagu y Nicita (2013) examinaron las políticas comerciales vigentes en 2009 en 131 países para detectar cambios introducidos a raíz de la crisis global. Estos autores encontraron que en la Argentina, China, Bolivia (Estado Plurinacional de), el Ecuador, la Federación de Rusia, Malawi y Turquía se había recurrido al aumento de las tarifas arancelarias, mientras que en los países de la Unión Europea y los Estados Unidos se había optado por la introducción de cargos de tipo antidumping.

En mayo de 2015, los aranceles de importación del Ecuador se aumentaron un 45\% ${ }^{9}$.

Dada la importancia de la balanza de pagos en la determinación del ahorro nacional y el crecimiento económico, en El Salvador se debería emular a los países desarrollados y recurrir a medidas proteccionistas en caso de recesión económica o apreciación de la moneda.

\section{Conclusiones}

En este trabajo se presenta evidencia de que la desindustrialización tiene efectos adversos en la economía salvadoreña en distintos sentidos, principalmente la disminución de la tasa de crecimiento económico y la tasa de ahorro nacional, el aumento de la economía subterránea y el deterioro de las cuentas externas y la inversión.

Cabe destacar que junto con la desindustrialización hubo un aumento del sector de servicios, con consecuencias negativas en el crecimiento económico. La desindustrialización dio lugar al deterioro del déficit en la cuenta comercial, que tiene una incidencia negativa en la inversión privada. De esa manera se crea un círculo vicioso en el que la desindustrialización inicial aumenta el déficit externo y, por ende, reduce la inversión privada, que por su parte agudiza la desindustrialización, incrementando aún más el déficit en cuenta comercial y así sucesivamente. En otros países latinoamericanos, la desindustrialización no ha tenido repercusiones tan adversas en el crecimiento económico como en El Salvador, en virtud del auge de los precios de los productos primarios registrado hasta hace poco. Sin embargo, ante el deterioro de estos precios, el papel negativo de la apertura se sentirá con mayor intensidad.

La causa determinante de la desindustrialización en El Salvador es la extrema apertura de la economía llevada a cabo en los años noventa en el marco del consenso de Washington. La evidencia

9 Publicado en BID (2015). El periódico The Washington Post del 26 de abril de 2015 informó que desde 2008 los países del Grupo de los 20 (G-20) agregaron 1.200 restricciones adicionales aplicables a las exportaciones e importaciones. 
empírica presentada en este trabajo también apunta a repercusiones adversas derivadas del amplio proceso de reformas de ese período.

Todo esto subraya la urgencia de restablecer la protección de la industria manufacturera y la agricultura nacional. Rodrik (1998) demostró que no había nada "ineficiente" con respecto a la sustitución de importaciones y que tampoco estaba "agotada" como se argumentó en los años noventa para justificar las reformas.

Los estudios sobre la implementación de medidas restrictivas al comercio internacional por los países desarrollados evidencian que en esos países el "libre comercio" tiene carácter discrecional: prevalece cuando sus circunstancias macroeconómicas son favorables, pero se deja de lado cuando sus industrias pueden resultar afectadas, por ejemplo por la apreciación de sus monedas. Los países como El Salvador deben emular estas sabias prácticas de los países desarrollados y aplicar medidas restrictivas a las importaciones, no solo como respuesta a la disminución del crecimiento económico o la sobrevaluación del tipo de cambio, sino con miras a establecer una protección que garantice el desarrollo de sus sectores productivos. En otras palabras, urge volver al régimen de sustitución de importaciones para incrementar la tasa de crecimiento económico y así combatir el desempleo, el subempleo y la violencia. Además, como señala Rodrik (2006), el modelo de apertura no tiene sustento histórico ni asidero conceptual, pues se basa en una serie de supuestos que difícilmente se dan en la realidad.

Esto tiene especial importancia en la actualidad, pues la caída de los precios de los productos primarios ha dado lugar a tendencias recesivas que habrá que contrarrestar. Seguir el ejemplo de los países desarrollados en cuanto a protección es una ruta de mucho valor.

Tregenna (2014) argumenta que la desindustrialización tenderá a cambiar la estructura y el carácter de la clase trabajadora, a medida que la mano de obra disminuye en el sector manufacturero - en el cual la organización de sindicatos de trabajadores no es tan compleja como en otros sectores - y crece en el sector de servicios, en el que la organización es ardua. Esto supone la necesidad de apoyar la creación y el crecimiento de organizaciones de trabajadores del sector de servicios para mantener la capacidad de negociación laboral de amplios sectores de la población. Además, Tregenna (2014) señala que la desindustrialización conduce a que la banca atienda con la más alta prioridad el financiamiento a corto plazo que demanda el sector de servicios, lo que resalta la importancia de la banca nacional de desarrollo para atender proyectos de los sectores productivos que requieran financiamiento a largo plazo.

Además de restituir la protección, es necesario aumentar la productividad del sector de servicios. Esto tiene importantes repercusiones en términos de género, en el sentido de que exige incrementar el valor agregado de amplios segmentos de la población femenina que trabajan en el sector subterráneo de la economía.

Los resultados de este trabajo evidencian el importante papel que desempeñan las corrientes comerciales desde El Salvador hacia los otros países centroamericanos en el combate a la desindustrialización. Se debe apoyar decididamente la integración centroamericana como medio para sustentar la industrialización. Este tema data de la obra de Prebisch (1949 y 1951), que argumentaba sobre la necesidad de la integración latinoamericana como medio para impulsar la exportación de bienes manufacturados, superar la restricción de la balanza de pagos y mejorar la tecnología y la productividad. Otros autores, posteriores a Prebisch, abogaron por la integración económica como instrumento para la industrialización (Balassa, 1961; Reynolds, 1968).

En El Salvador es necesario concebir la política económica como un mecanismo de construcción nacional. Se debe dar prioridad a la restitución del poder productivo para fomentar la generación de buenos empleos, la inversión, las exportaciones, la innovación y la cohesión social. El término "poder productivo" fue utilizado por List (1991, citado en Ho, 2005), para diferenciar 
su conceptualización de la economía política de la de otros connotados economistas (Smith, entre otros): la economía política no es la ciencia que enseña solo la manera en que los valores intercambiados son producidos por los individuos, distribuidos entre ellos y consumidos por ellos. Por encima de eso, trata de la manera en que el poder productivo de una nación puede despertarse, aumentarse y protegerse y, por otra parte, la manera en que este se debilita, adormece o destruye completamente, además de la manera en que, por medio de esos poderes productivos nacionales, los recursos nacionales pueden utilizarse de la manera más sabia y adecuada para generar existencia nacional, independencia nacional, prosperidad nacional, fortaleza nacional, cultura nacional y un futuro nacional.

Esos objetivos de independencia, prosperidad, cultura y futuro, elusivos en el contexto actual, deberían ser el objetivo principal de la política económica en El Salvador, que debe partir de la protección de los sectores productivos y del impulso a la igualdad de oportunidades.

\section{Bibliografía}

Balassa, B. (1961), The Theory of Economic Integration, Homewood, Illinois, Irwin.

Bennell, P. (1998), "Fighting for survival: manufacturing industry and adjustment in sub-Saharan Africa", Journal of International Development, vol. 10, № 5, Wiley.

BID (Banco Interamericano de Desarrollo) (2015), Noticias, Washington, D.C., 8 de junio [en línea] http:// www.iadb.org/es/noticias/noticias,2359.html.

Bown, Ch. y M.A. Crowley (2013), "Import protection, business cycles, and exchange rates: evidence from the Great Recession", Journal of International Economics, vol. 90, № 1, Amsterdam, Elsevier.

Brady, D., Y. Kaya y G. Gereffi (2008), "Why is Latin America deindustrializing?”, Universidad de Duke, inédito.

Cáceres, L.R. (2015), "Labor Productivity in Latin America", inédito.

Clavijo, S., A. Vera y R.A. Fandinho (2014), "Deindustrialization in Colombia: quantitative analysis of determinants", Working Paper, Bogotá, Asociación Nacional de Instituciones Financieras.

Clingingsmith, D. y J.G. Williamson (2005), "India's deindustrialization in the 18th and 19th centuries", Universidad de Harvard, inédito.

Dasgupta, S. y A. Singh (2006), "Manufacturing, services and premature de-industrialization in developing countries: a Kaldorian empirical analysis", Working Paper, № 327, Cambridge, Centre for Business Research, Universidad de Cambridge.

Díaz González, E. (2009), "Impactos de las remesas sobre la estabilidad macroeconómica: los casos de México y Centroamérica", Revista de la CEPAL, № 98 (LC/G.2404-P), Santiago, Comisión Económica para América Latina y el Caribe (CEPAL).

Dollar, D. y N. Wolff (1993), Competitiveness, Convergence, and International Specialization, Cambridge, Massachusetts, The MIT Press.

Frenkel, R. y M. Rapetti (2012), "External fragility or deindustrialization: what is the main threat to Latin American countries in the 2010's?", World Economic Review, № 1, Bristol, World Economic Association.

Ho, P. (2006), "Analyzing and arresting uneven development: Friedrich List and Gunnar Myrdal compared", Journal of Economic Issues, vol. 40, № 2, Taylor \& Francis. (2005), "Distortions in the trade policy for development debate: a re-examination of Friedrich List", Cambridge Journal of Economics, vol. 29, № 5, Oxford University Press.

IFC (Corporación Financiera Internacional) (1995), Trends in Private Investment in Developing Countries 1995: Statistics for 1980-93, Discussion Paper, № 25, Washington, D.C.

Instituto Salvadoreño del Seguro Social (2014), Anuario estadístico 2013, San Salvador.

Jalilian, H. y J. Weiss (2000), "De-industrialisation in sub-Saharan Africa: myth or crisis?", Journal of African Economies, vol. 9, № 1, Oxford University Press.

Kaldor, N. (1967), Strategic Factors in Economic Development, Ithaca, Cornell Univerity Press.

Kee, H., C. Neagu y A. Nicita (2013), "Is protectionism on the rise? Assessing national trade policies during the crisis of 2008-2009", Review of Economics and Statistics, vol. 95, № 1, Cambridge, Massachusetts, The MIT Press.

Knetter, M.M. y T.J. Prusa (2003), "Macroeconomic factors and antidumping filings: evidence from four countries", Journal of International Economics, vol. 61, № 1, Amsterdam, Elsevier. 
Lartey, E., F. Mandelman y P. Acosta (2008), "Remittances, exchange rate regimes and the Dutch disease: a panel data analysis”, Documento de Trabajo, Atlanta, Banco de la Reserva Federal de Atlanta.

Lawrence, R.Z. (1987), "Trade performance as a constraint on European growth", Barriers to European Growth: A Transatlantic View, R. Lawrence y C. Schultze (eds.), Washington, D.C., The Brookings Institution.

Lawrence, R.Z. y L. Edwards (2013), "US employment deindustrialization: insights from history and the international experience", Policy Brief, N 13-27, Washington, D.C., Peterson Institute for International Economics.

Lind, D. (2011), "The myths and reality of deindustrialization in Sweden: the role of productivity", International Productivity Monitor, vol. 22, Ottawa, Centre for the Study of Living Standards.

List, Friedrich (1991), The National System of Political Economy, Fairfield, Augustus M. Kelley. (1983), The Natural System of Political Economy 1837, Londres, Frank Cass.

Lora, E. (2012), "Las reformas estructurales en America Latina (version actualizada)", Documento de Trabajo, N ${ }^{\circ}$ IDB-WP-346, Washington, D.C., Banco Interamericano de Desarrollo.

Nickell, S., S. Redding y J. Swaffield (2008), "The uneven pace of deindustrialization in the OECD", The World Economy, vol. 31, N 9, Wiley.

Noorbakhsh, F. y A. Paloni (1999), "Structural adjustment programs and industry I Sub-Saharan Africa: restructuring or de-industrialization?", The Journal of Developing Areas, vol. 33, № 4, Nashville, Tennessee State University.

Palma, G. (2010), "Why has productivity growth stagnated in most Latin American countries since the neo-liberal reforms?", Cambridge Working Papers in Economics, № 1030, Cambridge, Universidad de Cambridge. (2008), "De-industrialization, 'premature' de-industrialization and the Dutch disease", The New Palgrave Dictionary of Economics, S.N. Durlauf y L.E. Blume (eds.), Londres, Palgrave Macmillan. (2005), "Four sources of 'de-industrialization' and a new concept of the Dutch-disease", Beyond Reforms: Structural Dynamic and Macroeconomic Vulnerabilty, J. A. Ocampo (ed.), Santiago, Comisión Económica para América Latina y el Caribe (CEPAL).

Phillips, P. y B. Hansen (1990), "Statistical inference in instrumental variables regressions with I(1) processes", Review of Economic Studies, vol. 57, N 1, Oxford University Press.

Pieper, U. (2003), "Sectoral regularities of productivity growth in developing countries - A Kaldorian interpretation", Cambridge Journal of Economics, vol. 27, Oxford, University Press.

Prasad, E., R. Rajan y A. Subramanian (2007), "Foreign capital and economic growth", Brookings Papers on Economic Activity, vol. 1, Washington, D.C., Brookings Institution.

Prebisch, R. (1951), Estudio económico de América Latina, 1949 (E/CN.12/164/Rev.1), Nueva York, Naciones Unidas.

(1949), El desarrollo económico de la América Latina y algunos de sus principales problemas (E/CN.12/89), Santiago, Comisión Económica para América Latina y el Caribe (CEPAL).

Reynolds, S.E. (1968), "Custom unions among developing countries", Malayan Economic Review, Kuala Lumpur, Universidad de Malaya.

Rodrik, D. (2015), "Premature deindustrialization", Economic Working Papers, N 107, Princeton, Instituto de Estudios Avanzados.

(2006), "Good bye Washington Consensus, hello Washington confusion", Journal of Economic Literature, vol. 44, N 4, Nashville, American Economic Association.

(1998), "Globalization, social conflict and economic growth", The World Economy, vol. 21, N², Nueva York, Wiley.

Rowthorn, R. (1994), "Korea at the cross roads", Documento de Trabajo, N 11, Cambridge, Centre for Business Research, Universidad de Cambridge.

Rowthorn, R. y R. Ramaswamy (1998), "Growth, trade and deindustrialization”, IMF Working Paper, N WP/98/60, Washington, D.C., Fondo Monetario Internacional.

Saeger, S. (1997), "Globalization and deindustrialization: myth and reality in the OECD", Weltwirschaftliches Archiv, vol. 133, Kiel, Springer.

Salama, P. (2012), "Globalización comercial: desindustrialización prematura en América Latina e industrialización en Asia", Comercio Exterior, vol. 62, № 6, Ciudad de México, Banco de Comercio Exterior.

Tahara, S. y H. Uemura (2013), "The transformations of growth regime and de-industrialization in Japan", Discussion Paper Series, N 2012-CEGS-02, Yokohama, Universidad Nacional de Yokohama.

Tregenna, F. (2014), "A new theoretical analysis of deindustrialization", Cambridge Journal of Economics, vol. 38, N 6, Oxford University Press. 
(2011), "Manufacturing productivity, deindustrialization, and reindustrialization", WIDER Working Paper Series, N57, Helsinki, Instituto Mundial de Investigaciones de Economía del Desarrollo (UNU-WIDER). Wells, H. y A. Thirlwall (2003), "Testing Kaldor's growth laws across the countries of Africa", African Development

Review, vol. 15, № 2-3, Banco Africano de Desarrollo.

\section{Anexo A1}

Cuadro A1.1

Pruebas de raíces unitarias

\begin{tabular}{lc}
\hline Variable & Prueba de Dickey-Fuller aumentada \\
\hline Agric & 1,8690 \\
\hline Manu & 2,2036 \\
\hline Agric+Manu & 1,9504 \\
\hline Remy & 2,1962 \\
\hline Gdpgrowth & 3,5353 \\
\hline RER & 0,8678 \\
\hline ExpCAy & 1,1324 \\
\hline Consumondy & 1,9946 \\
\hline Ipri & 3,3675 \\
\hline Grosssavings & 4,9742 \\
\hline Serv & 2,7143 \\
\hline TB & 2,4187 \\
\hline Arancelpromedio & 1,4525 \\
\hline Indicegeneral & 1,4558 \\
\hline
\end{tabular}

Fuente: Elaboración propia. 